\title{
Optimization for development of carbon nanotubes using Taguchi method at constant temperature
}

\begin{abstract}
In this study, an optimization of floating catalyst chemical vapor deposition (FC-CVD) using Taguchi method is done in developing multiwall nanotubes (MWNTs) at constant temperature. The reaction is run at the temperature of $850^{\circ} \mathrm{C}$ in atmospheric pressure with ferrocene as the catalyst precursor and benzene as the carbon feedstock. By applying Taguchiôs method as the design of experiment, three parameters: namely reaction time, hydrogen flow rate and catalyst weight have been varied during the optimization of the experiment. The results show that the BET specific surface area increases as the reaction time increases, the degree of graphitization reduces as the mass of the catalyst increases and the relative value of amorphous carbon to graphite carbon decreases as the hydrogen flow rate increases.
\end{abstract}

Keyword: Multiwall nanotubes; Taguchi method; Chemical vapour decomposition 